\title{
Multiple Acetabular Revisions in THA - Poor Outcome Despite Maximum Effort
}

\author{
O. Bischel ${ }^{*}, 1$, J.B. Seeger ${ }^{1}$, M. Krüger ${ }^{2}$ and B.G. Bitsch ${ }^{2}$ \\ ${ }^{I}$ Department of Orthopaedics and Orthopaedic Surgery, University Hospital Giessen-Marburg, UKGM, Klinikstrasse \\ 33, D-35392 Giessen, Germany \\ ${ }^{2}$ Department of Orthopaedics and Orthopaedic Surgery, University of Heidelberg, Schlierbacher Landstrasse 200a, \\ D-69118 Heidelberg, Germany
}

\begin{abstract}
A consecutive series of 52 acetabular revisions was evaluated retrospectively. Inclusion criteria for all patients were at least one former exchange of the acetabular component. Reconstruction was performed with reliable techniques and implants other than extensively porous coated device (e.g. tantalum). The mean follow up was 5.63 (0.01-14.05) years. Cumulative survival at 14.05 years with removal of the acetabular component due to aseptic loosening or the worst case criterion (removal of the acetabular component for any cause and/or lost to follow-up) as the end point was 66.38 (95 $\%$ C.-I.: 47.80-84.96) \% and 58.42 (95 \% C.-I.: 41.01-75.83) \%, respectively. The cumulative survival rate with mechanical failure of the acetabular reconstruction as the endpoint was significantly lower in patients with two or more previous revisions in comparison to those with only one former procedure ( $\log$ rank test: $\mathrm{p}=0,0112$ respectively). The mean Merle d'Aubignée-score improved from $7.3(0-14)$ preoperatively to $10.6(0-17)$ points at latest follow up examination.

Survival of acetabular reconstructions with common techniques and implants is decreasing with the number of previous revisions. This may cause major concerns with regard to the rising number of patients needing repeated revisions. Maximizing durability of primary THA, precise preoperative planning as well as improved techniques and implants for revision may decrease this problem in the long term.
\end{abstract}

Keywords: Hip arthroplasty, revision, tantalum, porous metal device, acetabular reconstruction.

\section{BACKGROUND AND PURPOSE}

Although hip arthroplasty has become one of the most reliable and successful procedures in orthopaedics, durability of joint reconstruction still is limited. As indication for primary joint replacement was widened constantly and due to the demographic change, the number of revisions is rising steadily. Projections for the next three decades based on actual data causes major concerns not only with regard to the large quantity of revisions but also to resulting costs $[1,2]$.

During the last three decades a great variety of implants and operative techniques for revision arthroplasty have been developed and some procedures established reliable results in medium to long term follow-up studies [3-9]. Patients after repeated exchange of implants undergoing a further revision may represent the most challenging cases. Durability of joint reconstruction is not only limited through excessive bone defects and resulting technical difficulties. Defect regeneration and implant integration is hindered by thinning and sclerosis of host bone stock.

There is no data available for a consecutive series of acetabular revisions in patients with more than one former

*Address correspondence to this author at the Department of Orthopaedics and Orthopaedic Surgery, University Hospital Giessen-Marburg, Klinikstrasse 33, D-35392 Giessen, Germany; Tel: +49-641-985-42616; Fax: +49641-985-42629; E-mail: Oliver.Bischel@ortho.med.uni-giessen.de acetabular replacement procedure. The aim of this study was to evaluate whether survival and functional outcome of acetabular revision procedures with established implants and techniques is influenced by the number of revisions.

\section{METHODS}

\section{Patients and Operative Technique}

A consecutive series of 52 acetabular hip revision arthroplasties in 39 patients performed in our institution between 1994 and 2005 was evaluated. 32 patients were female and seven were male, one was treated on both sides. All included cases had at least one former revision of the acetabular component (Table 1). Consecutive acetabular revisions on the same side due to failure were performed in nine patients (seven patients had two and two had three further revisions). All revisions were included in the study.

Reconstruction was done after removal of acetabular hardware with use of common implants and techniques (cemented low profile PE-cups, Mueller or Ganz roof reinforcement rings, Schneider Burch or Contour reconstruction rings) with or without frozen, non-irradiated allogenous bone grafts (Table 1). Metal wire mesh for coverage of a central acetabular defect was used in two hips; one in combination with morselized bone graft and an AR, the other with a cemented PE cup. 
Table 1. Summary

\begin{tabular}{|c|c|c|c|}
\hline \multicolumn{4}{|c|}{ Patients } \\
\hline No. of cases & \multicolumn{3}{|c|}{$\mathrm{N}=52$} \\
\hline Mean age at index operation (range) in years & \multicolumn{3}{|c|}{$65.9(38.4-89.0)$} \\
\hline Mean follow up in years & \multicolumn{3}{|c|}{$5.63(0.01-14.05)$} \\
\hline \multicolumn{4}{|l|}{ Indication for primary THA } \\
\hline Primary osteoarthritis $(\mathrm{OA})$ & \multicolumn{3}{|c|}{21} \\
\hline Secondary OA due to dysplasia & \multicolumn{3}{|c|}{17} \\
\hline Secondary OA after trauma & \multicolumn{3}{|c|}{8} \\
\hline Secondary OA due to avasc. necrosis/Perthes & \multicolumn{3}{|c|}{2} \\
\hline Secondary OA due to rheumatism & \multicolumn{3}{|c|}{4} \\
\hline \multicolumn{4}{|l|}{ Indication for index operation } \\
\hline Aseptic loosening & \multicolumn{3}{|c|}{42} \\
\hline Septic revision (one-stage/two-stage) & \multicolumn{3}{|c|}{$7(2 / 5)$} \\
\hline Recurrent dislocation & \multicolumn{3}{|c|}{2} \\
\hline Breakage of acetabular component & \multicolumn{3}{|c|}{1} \\
\hline Revised components & $\begin{array}{l}\text { Acetabulum } \\
\text { Acetabulum and femur }\end{array}$ & & $\begin{array}{l}29 \\
23\end{array}$ \\
\hline Side & $\begin{array}{l}\text { Left } \\
\text { Right }\end{array}$ & & $\begin{array}{l}20 \\
32 \\
\end{array}$ \\
\hline No. of acetabular revisions (index operation included) & $\begin{array}{l}2^{\text {nd }} \\
3^{\text {rd }} \\
4^{\text {th }} \\
5^{\text {th }} \\
6^{\text {th }}\end{array}$ & & $\begin{array}{r}27 \\
11 \\
8 \\
5 \\
1\end{array}$ \\
\hline \multicolumn{4}{|c|}{ Methods } \\
\hline \multirow[t]{3}{*}{ Surgical approach } & Anterior & & 5 \\
\hline & Transgluteal & & 39 \\
\hline & Transtrochanteric & & 8 \\
\hline \multirow[t]{3}{*}{ Acetabular component } & Cemented PE & & 8 \\
\hline & Roof Reinforcement Ring & & 29 \\
\hline & Reconstruction Ring & & 15 \\
\hline \multirow[t]{4}{*}{ Allogenous bone transplant } & None & & 8 \\
\hline & Massive & & 2 \\
\hline & Massive and Morselized & & 12 \\
\hline & Morselized & & 30 \\
\hline \multicolumn{4}{|c|}{ Results: function and defect situation } \\
\hline Merle d'Aubignée-score (range) in points & $\begin{array}{l}\text { Preop. } \\
\text { latest follow-up }\end{array}$ & & $\begin{array}{r}7.3(0-14) \\
10.6(0-17) \\
\end{array}$ \\
\hline Pain (range) in points & $\begin{array}{l}\text { Preop. } \\
\text { latest follow-up }\end{array}$ & & $\begin{array}{l}1.4(0-6) \\
3.4(0-6)\end{array}$ \\
\hline Movement (range) in points & $\begin{array}{l}\text { Preop. } \\
\text { latest follow-up }\end{array}$ & & $\begin{array}{l}4.4(0-6) \\
5.0(0-6)\end{array}$ \\
\hline Mobility (range) in points & $\begin{array}{l}\text { Preop. } \\
\text { latest follow-up }\end{array}$ & & $\begin{array}{l}1.5(0-5) \\
2.2(0-5)\end{array}$ \\
\hline No. of cases with 'poor/tolerable/good' Merle-Score $(<9,9-14,>14$ pts. $)$ & $\begin{array}{l}\text { Preop. } \\
\text { latest follow-up }\end{array}$ & & $\begin{array}{r}32 / 20 / 0 \\
13 / 31 / 8\end{array}$ \\
\hline Bone defect at latest follow-up (no. of cases) & $\begin{array}{l}\text { Increasing } \\
\text { Constant } \\
\text { Partial restoration } \\
\text { Complete }\end{array}$ & & $\begin{array}{l}12 \\
13 \\
13 \\
14\end{array}$ \\
\hline
\end{tabular}

Indication for primary THA and index operation and the number of revised acetabular and/or femoral components are summarized in table 1. Isolated revision of a failed femoral component was not performed after index operation. Radiologically all stems remained stable until latest followup. 
All operations were performed by 12 surgeons. 36 hips were revised by four surgeons who did more than five procedures in this collective. All patients were placed in supine position.

All patients were evaluated clinically and radiologically. The mean follow-up period was $5.61(0.01-14.05)$ years with the most recent follow-up, removal of the acetabular component for any cause or death as the end point (Table 1).

All clinical and radiological evaluation was performed by the same author. Various radiographic measurements were made as MRI and/or CT scans and X-ray films were available for all patients pre-, postoperatively and during follow-up. According to three common classification systems, only plane radiographs (a-p and lateral views) were used for preoperative assessment of the defect type (Table 2) [10-12]. Intraoperative description of the bone defect was also assessed for central, ventral, cranial and/or dorsal defects. A division of the deficiency into cavitary/contained, segmental/uncontained or combined defect was done. Quantitative radiographic determination of bone defect was performed preoperatively, immediately post-operatively and at latest follow-up. The latest follow-up radiographs were compared to post-operative $\mathrm{x}$-rays for any change in bone deficiency. Development of bone defect during follow up was rated as 'increasing', 'constant' and 'partial' or 'complete' osseous restoration.

Allografts were assessed for incorporation in host bone as evidenced by trabecular bridging of the host-graft interface. Breakdown of the transplanted bone or a clear reduction of density was defined as non-integration of the graft and bone resorption.

Pre- and postoperative functional assessment was done using the Merle d'Aubignée-score. Statistical analysis was performed with $\mathrm{JMP}^{\circledR} 8$ for Windows (SAS Institute Inc., Cary, North Carolina). A survivorship-analysis with $95 \%$ confidence intervals was performed using the Kaplan-Meier method with removal of the acetabular component/THA for mechanical failure/aseptic loosening, infection, instability and worst case (removal of the cup/THA for any cause and/or lost to follow up) as failure criteria. The $\mathrm{p}$-value for non-crossing survival curves were calculated with the log-rank-test, for crossing curves with the Wilcoxon-test. Associations or correlations between a continuous and/or discrete variable were tested by Student's T-, Paired T- or Chi square-test. All tests were two-sided and a $\mathrm{p}$ value $\leq 0.05$ was considered significant.

\section{RESULTS}

No patient was lost to follow-up, data was available for all cases $(n=52)$ until death, exclusion from the study or latest follow-up. Six patients died after a mean period of 6.50 (2.28-11.30) years after surgery. For analysis of the followup results, the data of these patients were included.

\section{Complications and Minor Revisions without Removal of Acetabular Component}

In one patient with a cavitary defect type II according to AAOS, fracture of the sclerotic bottom occurred during preparation of the acetabulum. A stable reconstruction was possible using massive and morselized allograft and an acetabular roof reinforcement ring with hook (AR). Dislocation of the hip occurred in seven cases. Until latest follow-up, six hips remained stable after closed reduction. Due to persisting instability despite exchange of the femoral head and acetabular liner four weeks before, replacement of a well fixed Ganz roof reinforcement ring by a SchneiderBurch reconstruction device was performed 0.74 years after index operation. The reconstruction stayed stable until latest follow-up.

Additional minor revisions without exchange of the THA occurred in four hips. One minor revision was necessary due to a fixed drain four days postoperatively. In this case, a two stage revision of THA was necessary due to low grade infection with removal of the hip arthroplasty 0.73 years postoperatively.

\section{Functional Evaluation}

The development of the Merle d'Aubignée-score and its underlying parameters (pain, movement, mobility) are summarized in (Table 1).

There was no significant difference neither between patients with only two compared to those with at least three revisions nor when the re-revisions were excluded with regard to pain, motion, mobility and Merle-score.

\section{Radiographic Evaluation}

Breakage of fixation screws of acetabular reconstructions during follow-up was visible in 15 cases. 13 of those migrated early and were revised due to aseptic loosening.

Preoperative defect classification is shown in table 2. Graft incorporation was visible in 33 of the 44 hips with allogenous bone transplants; complete ingrowth was stated in 17 cases. Two patients with bulk allograft alone showed no sign of incorporation. There was no significant relation between type of allograft (massive $v s$ morselized) and incorporation (partial or complete $v s$ non-integration).

Increasing bone defect at the acetabulum was stated in 12 , constant situation in 13 and an at least partial restoration of the defect in 27 (complete in 14) cases (table 1). Age,

Table 2. Bone Defect Classification (No. of Cases)

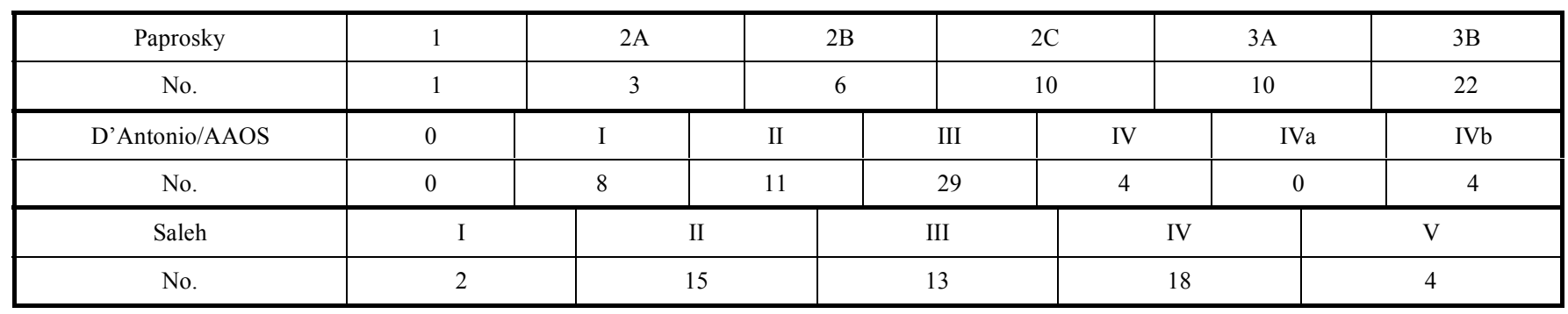


gender, body weight, number of previous operations, diabetes, and use of non-steroidal anti-inflammatory drugs, cortisone, alcohol or nicotine showed no influence on defect regeneration and/or integration of allogenous bone transplants.

\section{Survivorship Analysis}

17 hips needed rerevision. Survival of the acetabular reconstruction with the worst case criterion (removal due to any cause and/or lost to follow-up) or revision due to aseptic loosening (11 cases) was 58.42 (95 \% C.-I.: 41.01-75.83) \% and 66.38 (95 \% C.-I.: 47.80-84.96) \% after 14.05 years respectively (Figs. 1, 2). Repositioning of the acetabular component was performed 0.74 years after index operation in one case with recurrent dislocation despite exchange of the acetabular liner and femoral head four weeks before. The survival rate with instability as failure criteria was $97.92(95$ \% C.-I.: 93.88-100) \% after 14.05 years.

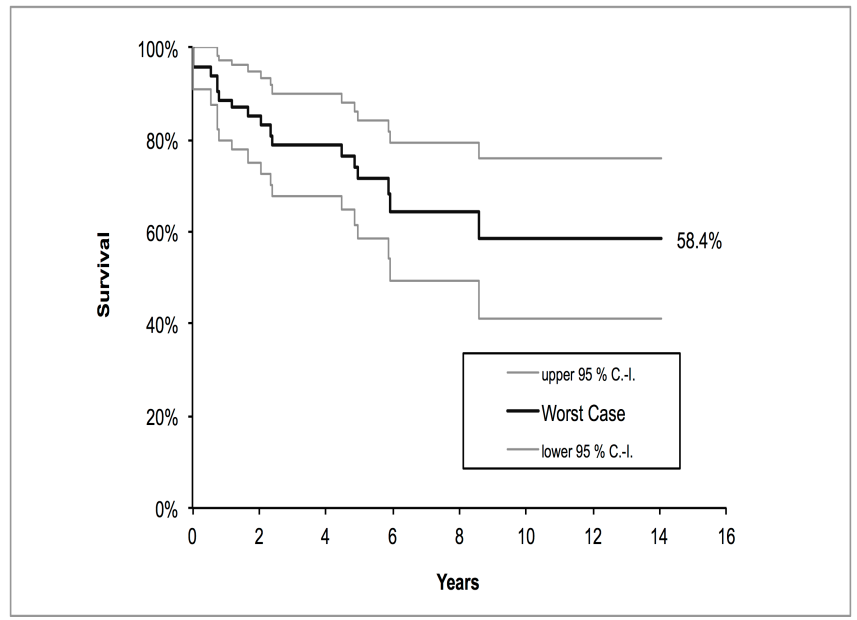

Fig. (1). Survivorship analysis: worst case criterion.

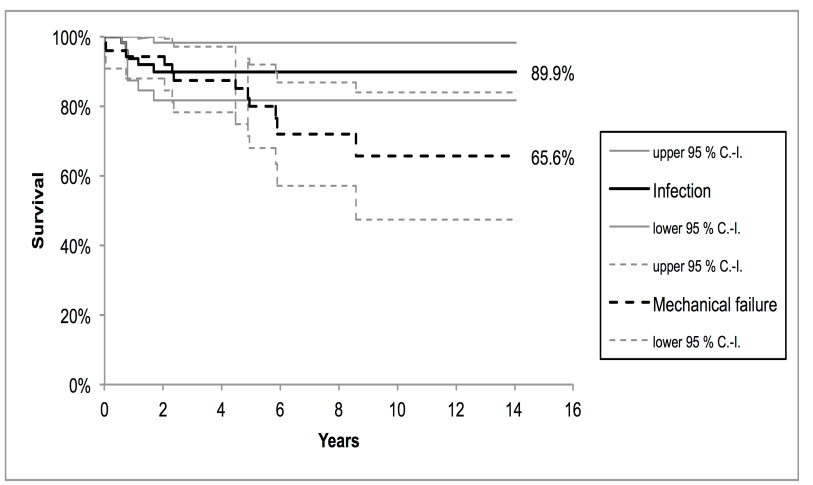

Fig. (2). Survivorship analysis: aseptic loosening and infection.

Removal of the acetabular component due to infection was necessary in five cases implying a cumulative survival rate of 89.87 (95 \% C.-I.: 41.01-75.83) \% after 14.05 years. Although three of them had former revisions due to infection, Wilcoxon test for crossing survival curves was not significant for the groups 'hips with former infection $(n=13)$ ' $v s$ 'no former infection until index operation $(\mathrm{n}=39)$ ' $(\mathrm{p}=0.0550)$.
Cumulative survival of the different reconstructions with aseptic loosening as the end point was $100 \%$ for the PE cups after 13.97 years, 58.77 (95\% C.-I.: 32.62-84.92) \% for the AR's after 11.30 years and 69.14 (95\% C.-I.: 38.25-100.00) $\%$ for RR's after 14.05 years. There was no significant difference of the survival of the used cup types neither for the worst case criterion (AS $v s$ RR: Wilcoxon test, $\mathrm{p}=0.4368$; PE vs RR: log rank test, $\mathrm{p}=0.8912$; PE vs AS: log rank test, $\mathrm{p}=0.7987$ ) nor for aseptic loosening (AS vs RR: Wilcoxon test, $\mathrm{p}=0.3713$; PE vs RR: log rank test, $\mathrm{p}=0.2432$; PE vs AS: log rank test, $\mathrm{p}=0.1649$ ).

With respect to defect classification systems, there was no correlation between the survival rates of the reconstruction and the grading of the different systems. Even a division within the systems (e.g. AAOS: type I vs II-IV; I+II vs III+IV or I-III vs IV; Paprosky: exclusion of the subtypes A, B, C and/or type 1 vs $2+3$ or $1+2$ vs 3 ) showed no tendency or significance.

There was no correlation between contained or uncontained defects and survival of the reconstruction. Survival was neither dependent on localization of a segmental defect (central, ventral, cranial or dorsal) nor on the number of concerned segments (only one, two, three or four deficient segments including the bottom).

Survival of the reconstruction with mechanical failure as the endpoint was significantly lower in patients with two or more previous revisions compared to those where the index operation was the second revision procedure (log rank test: $\mathrm{p}=0.0112$ ). Cumulative survival with mechanical failure as the endpoint was $91.7 \%$ after 14.05 years ( 2 out of 27 hips) versus $42.4 \%$ after 10.92 years (9/25 hips) (Fig. 3 ).

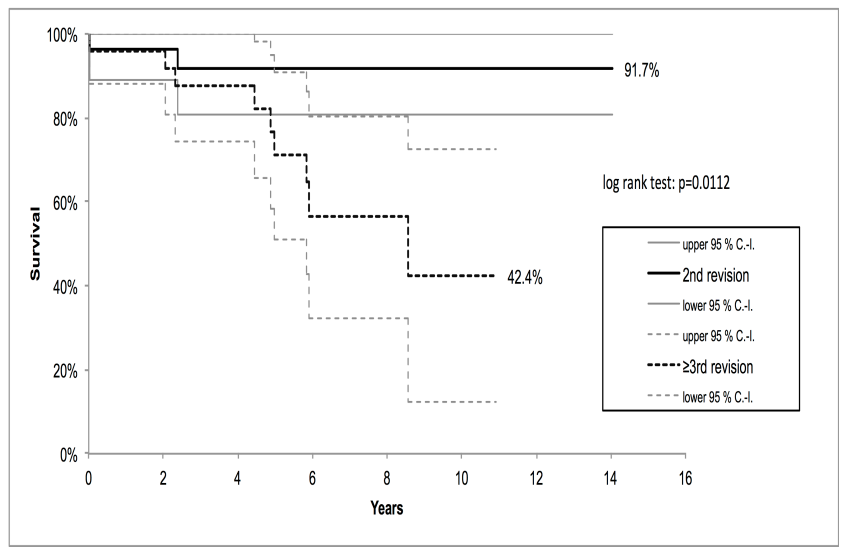

Fig. (3). Survivorship analysis (aseptic loosening): $2^{\text {nd }}$ vs. at least $3^{\text {rd }}$ revision at index operation.

\section{Interpretation}

To our knowledge there is no data about a consecutive series of patients after repeated acetabular reconstruction in THA. There are two publications after cemented re-revisions without detailed information with respect to the acetabular site $[13,14]$.

Final functional result of the patients in this study has to be considered as poor, though improvement of function between preoperative status and level at latest follow-up 
examination in this series using the Merle d'Aubignée-score was comparable to other series $[15,16]$.

The only factor in this series showing significant influence on survival rate was the number of previous revisions. Cumulative survival in this series with removal of the implant due to mechanical failure as the endpoint was significantly lower in patients with only one former revision compared to those with two or more revisions.

Although this study showed no influence of quantitative bone defect on survival of the acetabular component, estimating bone deficiency and bone quality is mandatory for preoperative assessment of surgical procedure and choice of implant in revision THA [20]. Classification should not be descriptive but only relay on biomechanical aspects for individual assessment of the proceeding.

There are frequently used classifications for determination of acetabular bone loss $[10,12]$. The systems described by Paprosky and Magnus and the one of Saleh et al., are based on x-ray evaluation of standard anteroposterior (pelvic) and lateral views of the hip. Although Saleh reports a high preoperative interobserver reliability and intraoperative validity of his graduation, underestimation of the defect may occur. Additional x-ray magnetic resonance or computer tomography revealed greater bone loss especially at the posterior wall and ischium compared to the estimation according to Paprosky and Magnus based on standard two plain radiographs [21-24]. Underestimation of a defect may lead to treatment by not suitable implants and consecutively to a high failure rate. Cementless cups, roof reinforcement rings or impaction grafting in combined medial deficiencies and/or uncontained defects at the posterior wall or even pelvic discontinuities revealed higher failure rates compared to the use of antiprotrusio cages in these cases $[6,9,25]$. Therefore, preoperative assessment of the quantity of bone loss using only plane radiographs may be too imprecise and consecutively, not sufficient for a suitable preoperative planning.

Not only the amount of bone loss may increase with the number of previous replacements but also quality and vitality of the remaining host bone stock is decreasing due to sclerosis (Figs. 4-8). High contact area to vital cancellous bone is necessary for ingrowth of cementless implants and/or bone transplants as well as for primary stability in cement fixation [26]. Breaking the sclerosis of the thin floor to get this presupposition is limited or impossible as acetabular or pelvic stability is weakened additionally. Although contact area between host bone and implant can be improved with custom made implants, influence of bone vitality may be one of the reasons for the great variety of survival rates of same implants in different studies [27-30].

Overall survival rate after 14.05 years with the worstcase criterion (any cause and/or lost to follow up) or aseptic loosening as the end point was $58.42 \%$ or $66.38 \%$. The revision rates due to aseptic loosening with regard to RR's and AR's were $58.77 \%$ after 11.30 years and $69.14 \%$ after 14.05 years and worse to comparable series published yet [3, $4,9,17-19]$. The revision rate due to infection or instability was comparable to these series.

Neither the defect classification systems nor intraoperative defect description correlated with a mechanical failure of the reconstruction. In addition, general patients or specific intraoperative data showed no significant influence on survival of the reconstruction. Both findings were similar to those of Sembrano et al., [4].

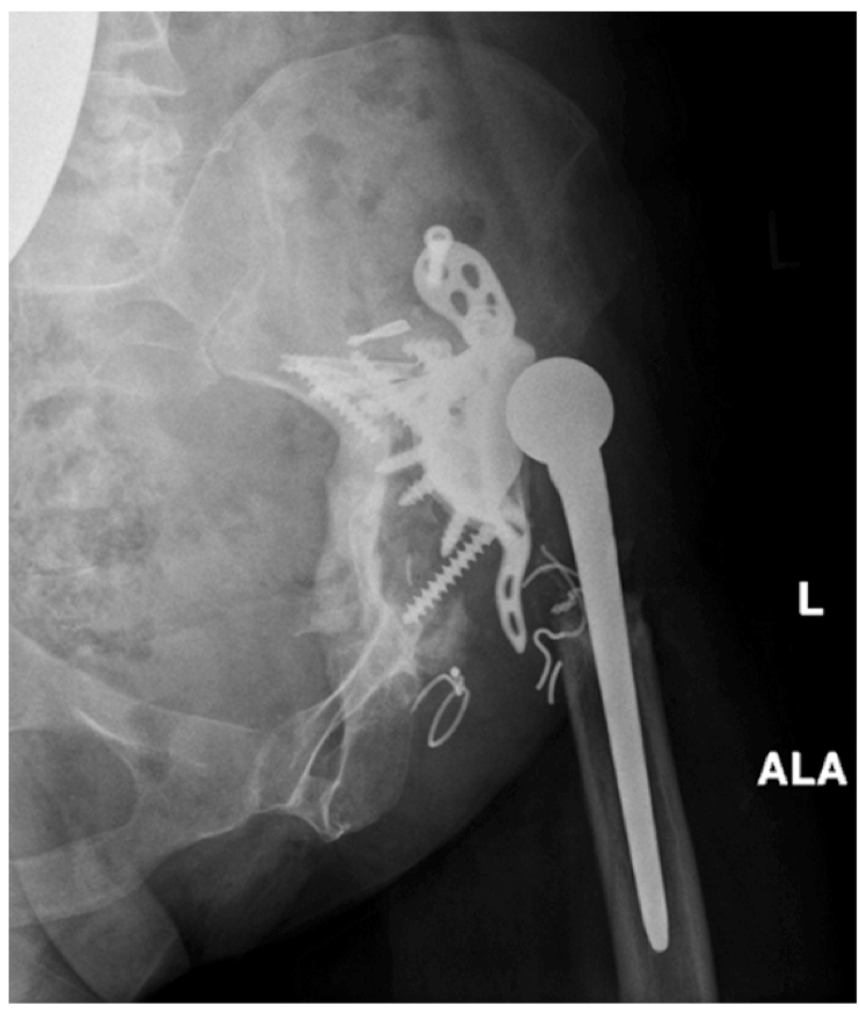

Fig. (4). Compared to standard views (Fig. 2) additional information with respect to the bony defect situation can be obtained with further radiological diagnostics. In this case, simple oblique iliac radiograph shows a highly deficient posterior wall, massive sclerosis of the host bone and defects at the bottom due to loosening and dislocation of screws.

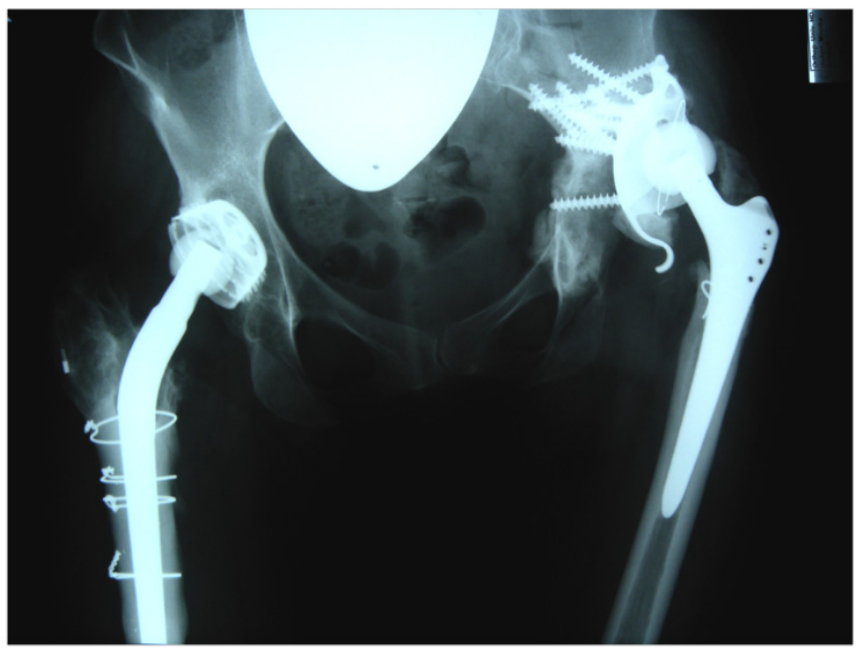

Fig. (5). This ap radiograph of the pelvis is showing a dislocation of an acetabular reconstruction by reinforcement ring with hook and allogenous, morselized bone graft 6 months after the $4^{\text {th }}$ revision procedure elsewhere. This female patient was 49 years old at index operation. Primary THA was performed at the age of 42 years due to developmental dysplasia of the hip.

Even with use of more porous metal implants or augments instead of bone grafts with a proven high 
osteoinductivity, integration of these implants into thinned and sclerotic bone may be also limited although encouraging short to mid-term results in some studies has been already reported [16, 31-36]. Fragility of this material may cause wear debris and the high surface may be related with higher infection rates in the long run.

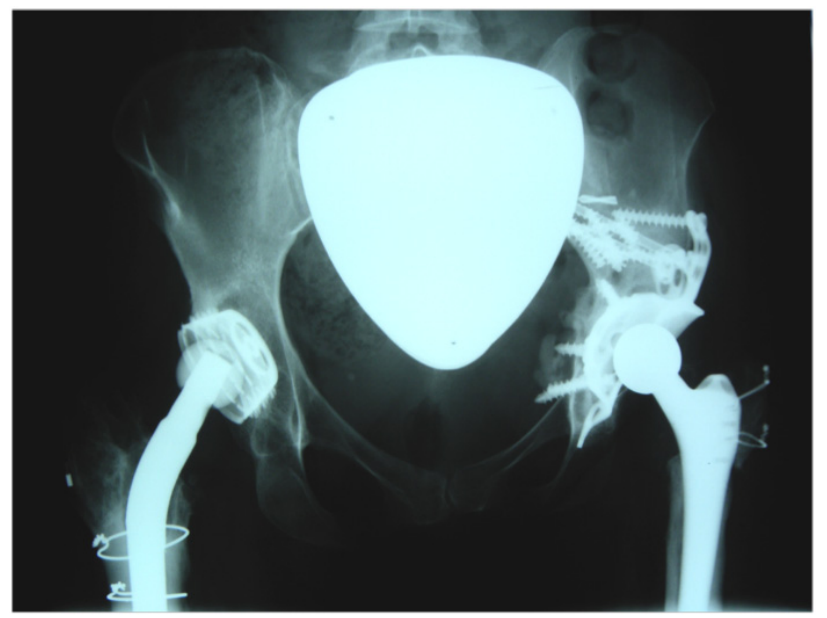

Fig. (6). 14 days postoperatively after a standard reconstruction by allogenous, morselized bone graft and reconstruction ring (antiprotrusio cage).

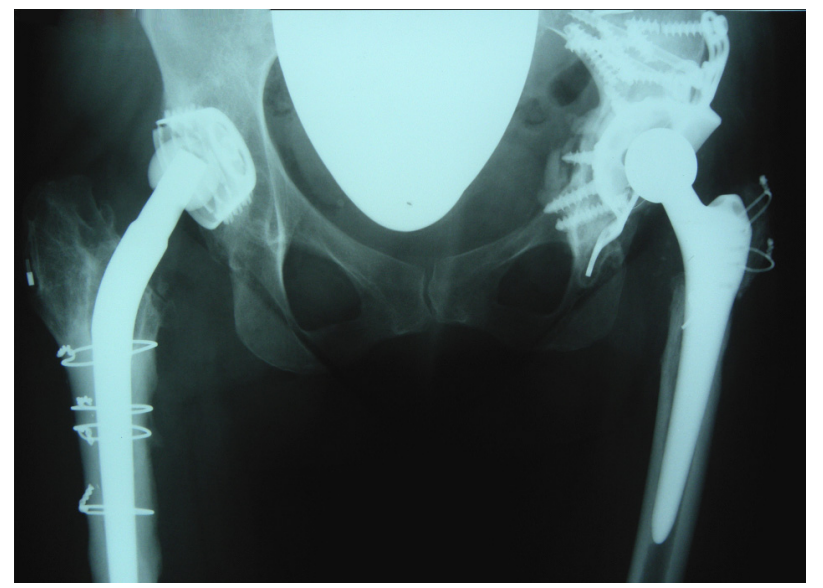

Fig. (7). A (primary,) stable situation was present for over one year. 15 months postoperatively, breakage of screws and slight migration of the construct was revealed for the first time after regular followup indicating non integration of bone transplant and/or implant due to massive sclerosis.

In general, biological reconstruction by use of autologous grafts for defect augmentation is favourable to allograft bone but host bone is limited. The rate of ingrowths of morselized allograft is higher compared to massive allografts but the latter are often necessary to get primary stability in noncontained defects [37-40]. One of the golden standards of acetabular revision in case of non-contained bone defects is the use of allogenous bone graft and specific revision devices like roof reinforcement rings or antiprotrusio cages $[3,4,9,17,18,25,41]$. Limited survival of these reconstructions also is related to none integration of allograft into host bone. Bone ingrowth can be enhanced by osteoinduction. The use of stem cells in combination with allograft bone may improve incorporation and therefore survival of the implant [42]. In-vitro and animal studies with biogenetic agents like osteogenetic proteins or bone morphogenetic protein have shown advanced integration but clinical data is missing [43].

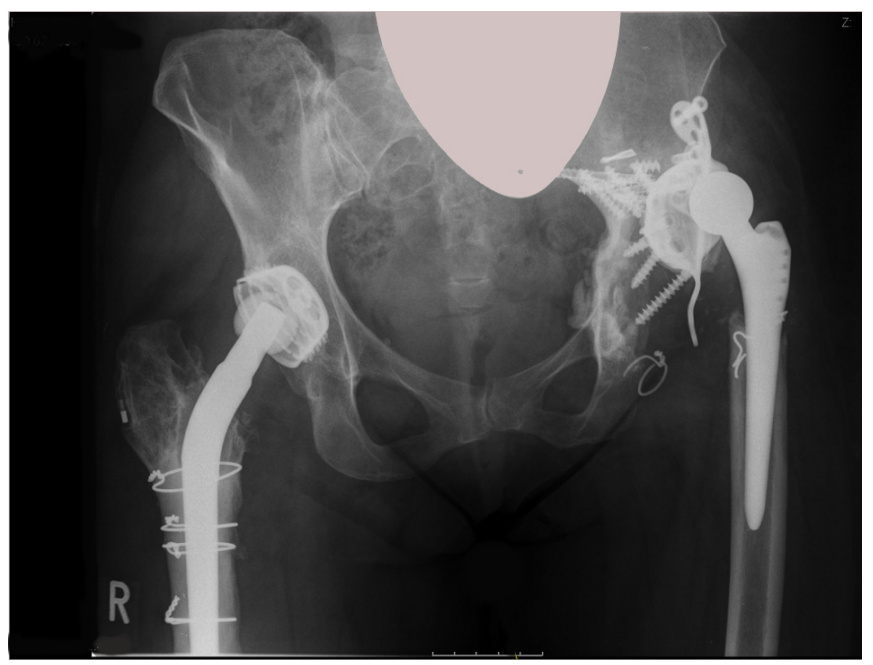

Fig. (8). Sudden dislocation occurred less than six years after the index operation leading to the $6^{\text {th }}$ revision procedure due to immobility and pain.

\section{CONCLUSION}

Patients presenting with repeated implant failure in THA are demanding not only with respect to the rising number. Although this study has some limitations, it is the first investigation dealing with a consecutive series of patients undergoing acetabular revision for at least the second time within a mid- to long-term follow-up period.

Functional outcome in this series is poor. Survival of acetabular reconstruction with contemporary techniques and implants is very limited and decreasing with the number of previous revisions. There was a significantly lower survival of acetabular reconstruction in patients with two or more former revisions compared to patients with only one previous acetabular replacement procedure.

Although very promising short term data with more porous metal devices exist, future examination and long term follow-up studies in a large number of patients may give definitive answer whether these implant generation will give better results especially in these most challenging patients.

\section{CONTRIBUTIONS OF AUTHORS}

Each of the authors hereby transfers, assigns and otherwise conveys to the journal all right, title and interest in the work, including but not limited to any and all copyrights therein held by each undersigned author.

Each of the authors hereby warrants, represents and covenants that each of the authors has read and approved the final manuscript or version of the work; the work is original.

\section{CONFLICT OF INTEREST}

The authors confirm that this article content has no conflict of interest.

\section{ACKNOWLEDGEMENTS}

Declared none. 


\section{REFERENCES}

[1] Kurtz S, Ong K, Lau E, Mowat F, Halpern M. Projections of primary and revision hip and knee arthroplasty in the United States from 2005 to 2030. J Bone Joint Surg Am 2007; 89(4): 780-5.

[2] Pedersen AB, Johnsen SP, Overgaard S, Søballe K, Sørensen HT, Lucht U. Total hip arthroplasty in Denmark: incidence of primary operations and revisions during 1996-2002 and estimated future demands. Acta Orthop 2005; 76(2): 182-9.

[3] Schlegel UJ, Bitsch RG, Pritsch M, Clauss M, Mau H, Breusch SJ. Mueller reinforcement rings in acetabular revision: outcome in 164 hips followed for 2-17 years. Acta Orthop 2006; 77(2): 234-41.

[4] Sembrano JN, Cheng EY. Acetabular cage survival and analysis of factors related to failure. Clin Orthop Relat Res 2008; 466(7): 1657-65.

[5] Regis D, Magnan B, Sandri A, Bartolozzi P. Long-term results of antiprotrusion cage and massive allografts for the management of periprosthetic acetabular bone loss. J Arthroplasty 2008; 23(6): 826-32.

[6] Buttaro MA, Comba F, Pusso R, Piccaluga F. Acetabular revision with metal mesh, impaction bone grafting, and a cemented cup. Clin Orthop Relat Res 2008; 466(10): 2482-90.

[7] Sporer SM, O'Rourke M, Chong P, Paprosky WG. The use of structural distal femoral allografts for acetabular reconstruction. Surgical technique. J Bone Joint Surg Am 2006; 88 (Suppl): 92-9.

[8] Della Valle CJ, Berger RA, Rosenberg AG, Galante JO. Cementless acetabular reconstruction in revision total hip arthroplasty. Clin Orthop Relat Res 2004; 420: 96-100.

[9] Gerber A, Pisan M, Zurakowski D, Isler B. Ganz reinforcement ring for reconstruction of acetabular defects in revision total hip arthroplasty. J Bone Joint Surg Am 2003; 85-A(12): 2358-64.

[10] D'Antonio JA, Capello WN, Borden LS, et al. Classification and management of acetabular abnormalities in total hip arthroplasty. Clin Orthop Relat Res 1989; 243: 126-37.

[11] Paprosky WG and Magnus RE. Principles of bone grafting in revision total hip arthroplasty. Acetabular technique. Clin Orthop Relat Res 1994; $298:$ 147-55

[12] Saleh KJ, Holtzman J, Gafni A, et al. Reliability and intraoperative validity of preoperative assessment of standardized plain radiographs in predicting bone loss at revision hip surgery. J Bone Joint Surg Am 2001; 83-A(7): 1040-6.

[13] Retpen JB, Varmarken JE, Röck ND, Jensen JS. Unsatisfactory results after repeated revision of hip arthroplasty. 61 cases followed for 5 (110) years. Acta Orthop Scand 1992; 63(2): 120-7.

[14] Retpen JB, Jensen JS. Risk factors for recurrent aseptic loosening of the femoral component after cemented revision. J Arthroplasty 1993; 8(5): 471-8.

[15] Sporer SM, O'Rourke M, Chong P, Paprosky WG. The use of structural distal femoral allografts for acetabular reconstruction. Average ten-year follow-up. J Bone Joint Surg Am 2005; 87(4): 760-5.

[16] Lakstein D, Backstein D, Safir O, Kosashvili Y, Gross AE. Trabecular Metal cups for acetabular defects with $50 \%$ or less host bone contact. Clin Orthop Relat Res 2009; 467(9): 2318-24.

[17] Bohm P, Banzhaf S. Acetabular revision with allograft bone. 103 revisions with 3 reconstruction alternatives, followed for 0.3-13 years. Acta Orthop Scand 1999; 70(3): 240-9.

[18] Winter E, Piert M, Volkmann R, et al. Allogeneic cancellous bone graft and a Burch-Schneider ring for acetabular reconstruction in revision hip arthroplasty. J Bone Joint Surg Am 2001; 83-A(6): 862-7.

[19] Carroll FA, Hoad-Reddick DA, Kerry RM, Stockley I. The survival of support rings in complex acetabular revision surgery. J Bone Joint Surg Br 2008; 90(5): 574-8.

[20] Deirmengian GK, Zmistowski B, O'Neil JT, Hozack WJ. Management of acetabular bone loss in revision total hip arthroplasty. J Bone Joint Surg Am 2011; 93(19): 1842-52.

[21] Garcia-Cimbrelo E, Tapia M, Martin-Hervas C. Multislice computed tomography for evaluating acetabular defects in revision THA. Clin Orthop Relat Res 2007; 463: 138-43.

[22] Zimlich RH, Fehring TK. Underestimation of pelvic osteolysis: the value of the iliac oblique radiograph. J Arthroplasty 2000; 15(6): 796801 .
[23] Weiland DE, Walde TA, Leung SB, et al. Magnetic resonance imaging in the evaluation of periprosthetic acetabular osteolysis: a cadaveric study. J Orthop Res 2005; 23(4): 713-9.

[24] John JF, Talbert RE, Taylor JK, Bargar WL. Use of acetabular models in planning complex acetabular reconstructions. J Arthroplasty 1995; 10(5): 661-6.

[25] Schatzker J, Wong MK. Acetabular revision. The role of rings and cages. Clin Orthop Relat Res 1999; 369: 187-97.

[26] Patil N, Hwang K, Goodman SB. Cancellous impaction bone grafting of acetabular defects in complex primary and revision total hip arthroplasty. Orthopedics 2012; 35(3): 306-12.

[27] DeBoer DK, Christie MJ, Brinson MF, Morrison JC. Revision total hip arthroplasty for pelvic discontinuity. J Bone Joint Surg Am 2007; 89(4): 835-40.

[28] Moskal JT, Higgins ME, Shen J. Type III acetabular defect revision with bilobed components: five-year results. Clin Orthop Relat Res 2008; 466(3): 691-5.

[29] Chen WM, Engh CA Jr, Hopper RH Jr, McAuley JP, Engh CA. Acetabular revision with use of a bilobed component inserted without cement in patients who have acetabular bone-stock deficiency. J Bone Joint Surg Am 2000; 82(2): 197-206.

[30] Holt GE, Dennis DA. Use of custom triflanged acetabular components in revision total hip arthroplasty. Clin Orthop Relat Res 2004; 429: 20914.

[31] Kim WY, Greidanus NV, Duncan CP, Masri BA, Garbuz DS. Porous tantalum uncemented acetabular shells in revision total hip replacement: two to four year clinical and radiographic results. Hip Int 2008; 18(1): 17-22.

[32] Kosashvili Y, Backstein D, Safir O, Lakstein D, Gross AE. Acetabular revision using an anti-protrusion (ilio-ischial) cage and trabecular metal acetabular component for severe acetabular bone loss associated with pelvic discontinuity. J Bone Joint Surg Br 2009; 91(7): 870-6.

[33] Nehme A, Lewallen DG, Hanssen AD. Modular porous metal augments for treatment of severe acetabular bone loss during revision hip arthroplasty. Clin Orthop Relat Res 2004; 429: 201-8.

[34] Siegmeth A, Duncan CP, Masri BA, Kim WY, Garbuz DS. Modular tantalum augments for acetabular defects in revision hip arthroplasty. Clin Orthop Relat Res 2009; 467(1): 199-205.

[35] Sporer SM, Paprosky WG. Acetabular revision using a trabecular metal acetabular component for severe acetabular bone loss associated with a pelvic discontinuity. J Arthroplasty 2006; 21(6 Suppl 2): 87-90.

[36] Weeden SH, Schmidt RH. The use of tantalum porous metal implants for Paprosky 3A and 3B defects. J Arthroplasty 2007; 22(6 Suppl 2): 151-5.

[37] Heekin RD, Engh CA, Vinh T. Morselized allograft in acetabular reconstruction. A postmortem retrieval analysis. Clin Orthop Relat Res 1995; 319: 184-90.

[38] Hooten JP. Jr, Engh CA, Heekin RD, Vinh TN. Structural bulk allografts in acetabular reconstruction. Analysis of two grafts retrieved at post-mortem. J Bone Joint Surg Br 1996; 78(2): 270-5.

[39] Hirose I, Kawauchi K, Kondo S, et al. Histological evaluation of allograft bone after acetabular revision arthroplasty: report of two cases. J Orthop Sci 2000; 5(5): 515-9.

[40] van der Donk S, Buma P, Slooff TJ, Gardeniers JW, Schreurs BW. Incorporation of morselized bone grafts: a study of 24 acetabular biopsy specimens. Clin Orthop Relat Res 2002; 396: 131-41.

[41] Pieringer H, Auersperg V, Bohler N. Reconstruction of severe acetabular bone-deficiency: the Burch-Schneider antiprotrusio cage in primary and revision total hip arthroplasty. J Arthroplast 2006; 21(4): 489-96.

[42] Ochs BG, Schmid U, Rieth J, Ateschrang A, Weise K, Ochs U. Acetabular bone reconstruction in revision arthroplasty: a comparison of freeze-dried, irradiated and chemically-treated allograft vitalised with autologous marrow versus frozen non-irradiated allograft. J Bone Joint Surg Br 2008; 90(9): 1164-71.

[43] Cook SD, Barrack RL, Patron LP, Salkeld SL. Osteoinductive agents in reconstructive hip surgery: a look forward. Clin Orthop Relat Res 2003; 417: $195-202$ 